\title{
Characterization by SIMS of Silicon Layer Deposited by VPE on SiP in the Solar Cells with Thin Layers
}

\author{
Malika Madani ${ }^{1}$, Amaria Bensaoula ${ }^{1}$, Fethi Benkhenafou ${ }^{1,3}$, Wen Shi ${ }^{3}$,WeiWei DU ${ }^{2}$ and Lyes Douadji ${ }^{3 *}$ \\ ${ }^{1}$ Physics department, University of Tlemcen, Tlemcen City, Algeria \\ ${ }^{2}$ Faculty of Materials and Energy, Southwest University BeiBei District, Chongqing City, China \\ ${ }^{3}$ Chongqing Academy of Science and Technology, 2 Yangliu Road, Huangshan Avenue, New North Zone Chongqing 410123, \\ China \\ ${ }^{*}$ Corresponding author
}

\begin{abstract}
Classically, in the field of photovoltaic, porous silicon (PS) is used as an antireflecting layer, but these last years, we are interested in a new application of this material, which allows, by technologies very different from proceed usual to detach from the singlecrystal thin layers from a substrate. An electrochemical attack is carried out on a silicon substrate, with times and densities of current variable so as to obtain two layers of gradual porosities being formed from surface (strong porosity in-depth). We carry out then a hydrogenation (to passivate the structure), an epitaxy in liquid phase (LPE) or Vapor Phase Epitaxy (VPE), and then we carry out the cell. During the temperature treatment high, porous silicon is recristallized partially. Then separation is made once the cell carried out, by sticking a transparent plastic film on surface and by applying a weak force (the PS being used as sacrificial layer). In this study, a characterization by secondary spectroscopy of mass of the ions (SIMS) informs us about the level of doping and the concentration of the carriers, and, electronic microscopy has sweeping (SEM) informs us about porous morphologies of these layer.
\end{abstract}

Keywords - SIMS; photovoltaic; silicon; characterization

\section{INTRODUCTION}

The crystalline silicon cells with thin layer are of great interest in the photovoltaic field. However the direct realization of such cells requires a plug layer having to play the part of support for the epitaxy layer. However, the realization of porous silicon requires only simple means: an anodization of single-crystal silicon in hydrofluoric acid and methanol. Its application extended in several fields such as the electroluminescent diodes [ 1 ], the thermal sensors [ 2 ], of gas [ 3 ], in technique SOI [ 4,5], and the photovoltaic [ 6-7 ]. Growth of the layers epitaxy this fact by VPE or epitaxy in liquid phase (LPE) on the porous, it remained however to find a mean to separate the layer epitaxy in order to stick it on a substrate to low cost like ceramics. This problem was solved [8] by using a porous layer gradual (low porosity over and strong below). To carry out single-crystal silicon solar cells at low costs, porous silicon as its detachment is thus of a great need, in this direction, some techniques of detachment of porous (layer epitaxy on porous) were brought back in the literature of which we quote here, the technique of separation using a solution of attack based on $\mathrm{HF} / \mathrm{H}_{2} \mathrm{O}_{2}$ using an agitation by ultrasounds [9]. Other techniques can be also used like separation by irradiation and/or ultrasounds [8]. Porous silicon has in addition other advantages; indeed, after the stage of separation, stage which follows the growth of an LPE, the diffusion (junction $n+/ p$ ), the realization of the contacts interdigities, and the stage of joining of the structure on the face comprising the contacts. We find then with porous silicon in front face of solar cell. This layer of strong porosity, was find thus opposite before cell, can be used like sleep anti-reflecting. The purpose of this work is to study the evolution of the microstructure of mésoporous silicon according to the different thermics treatment necessary to the technological stages from realization of the thin solar cells which we summarize as follows: (i) realization of a layer of gradual porosity, followed by (ii) growth of a layer of Si by VPE or LPE on the less porous layer, (iii) stage of diffusion of doping agent to form the junction $n+/ p$, then (iv) the realization of the contacts and separation of the unit and after joining on inexpensive substrate. Our work is to characterize these porous layers by SIMS and (SEM). [10-11].

\section{EXPERIMENTAL PROCEDURES}

The porous structures are obtained by anodic treatment of substrate of Si of type P, of orientation (100) and (111) and resistivity $0.01-0.025 \mathrm{~W} . \mathrm{cm}$. This electrochemical attack is carried out in a solution of $[\mathrm{HF}]$ : $\mathrm{C} 2 \mathrm{H} 5 \mathrm{OH}$, with densities of current of 5, 30 and $75 \mathrm{~mA} / \mathrm{cm}^{2}$ during 2, 3, 10 and $20 \mathrm{~min}$. The density of current as well as the selected time of attack make it possible to carry out gradually porous layers; this choice was preceded several tests in order to optimize the conditions of realization of such layers. We obtained a low porosity on the surface and more important in-depth.

\section{A. Anealing under Hydrogen}

We will have the results relating to annealing under hydrogen of structure bi-layer of porous silicon. [12].

\section{B. Bi-layer Realized without Modification of Concentration [HF] during Anodization}

The layers of low porosity ( $p=20 \%, e \approx 1 \mu \mathrm{m}$ ) and strong porosity $(p=50 \%, e \approx 1,5 \mu \mathrm{m})$ of bi-layer presented on the figure. 1 were carried out with the same concentration in hydrofluoric acid $[\mathrm{HF}]=25 \%$ of the solution of anodization. Only the packing of current from 5 to $75 \mathrm{mAcm}^{-2}$ ensures the modification of porosity. Observation SEM of the layer of low 
porosity before annealing (fig. 1 a)) and after annealing (fig. 1 b)) does not detect any structural modification.

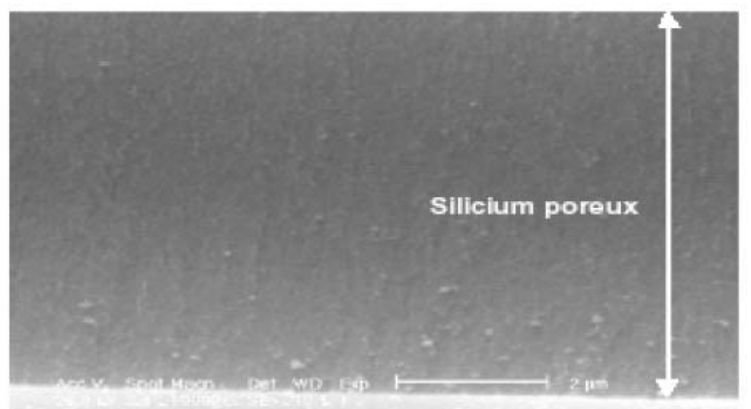

a) Before annealing

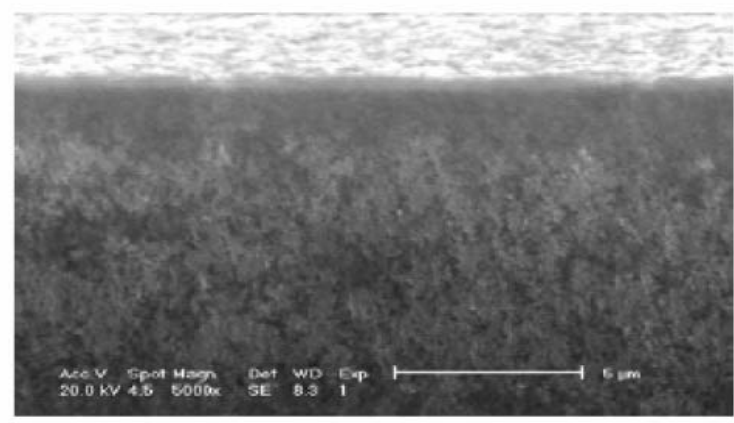

b) After annealing

FIGURE I. BI-LAYER BEFORE AND AFTER ANNEALING UNDER HYDROGEN, (VPE), SOLUTION $[\mathrm{HF}]=25 \% . \mathrm{J}=5 / 75 \mathrm{MA} . \mathrm{CM}^{-2}, \mathrm{P}=20 / 50$

\section{Bi-layer realized with modification of concentration [HF] during anodization}

The photographs presented make it possible to appreciate the reorganization of the porous layers

- For the layer of low porosity, porosity with the interfaces (on the surface and between the two porous layers) is closed. In parallel, the pore in volume has form spherical cavities.

- For the layer of strong porosity, the reorganization leads to the formation of a fragile layer made of empty spaces separated by silicon columns (substrate (111)). By comparing these results with those obtained without modifying the solution of anodization, noticing us that the reorganization of the layer of strong porosity is here form accentuated.

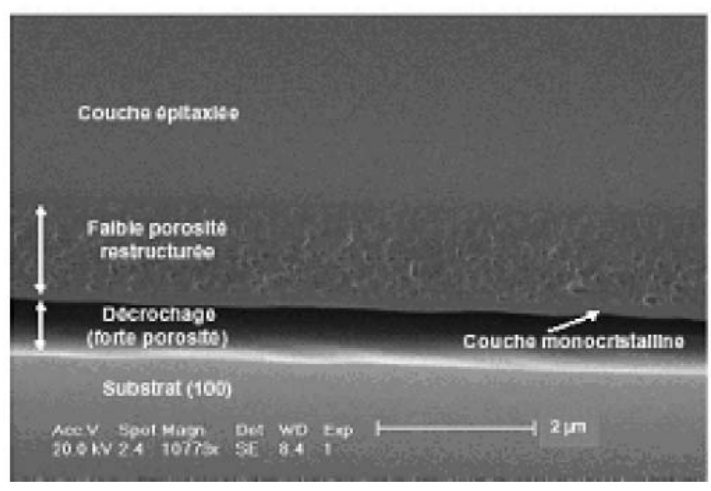

a) Oriented substrate (100)

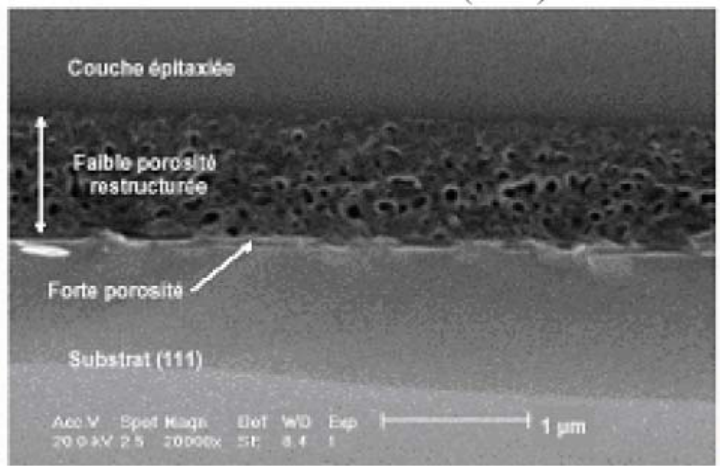

b) Oriented substrate (111)

FIGURE II. POROUS BI-LAYER AFTER ANNEALING UNDER HYDROGEN AND EPITAXY (VPE), $J=5 M A . C M-2,[H F]=25 \%$, THEN $J$ $=30 M A \cdot C M-2,[H F]=12,5 \%$.

\section{GROWTH OF LAYER EPITAXY BY LPE}

We made grow by LPE a thin layer of silicon (a few tens of $\mu \mathrm{m})$ on sample Si-p (100) and on a sample in Si-p (111) of 20\% of porosity (elaborate under the same conditions) [13].

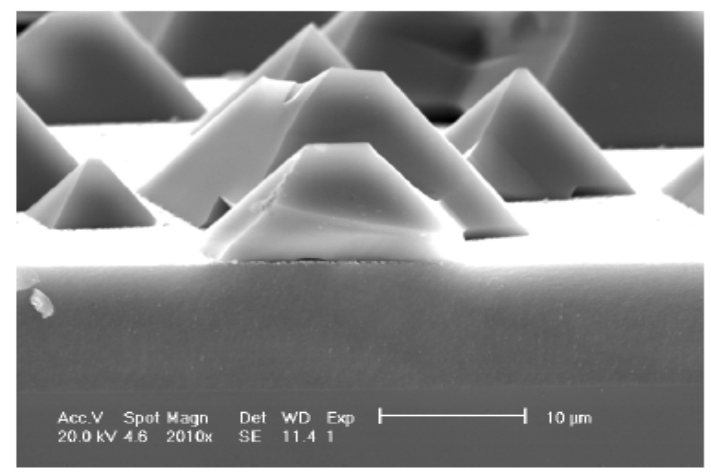

(a) 


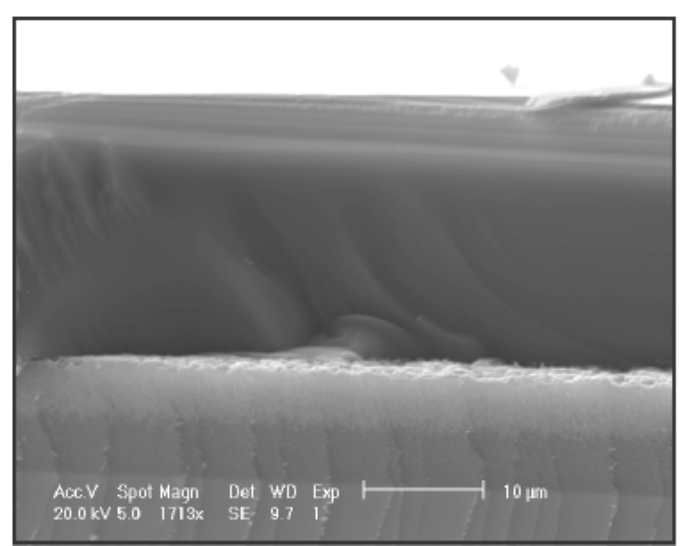

(b)

FIGURE III. ANALYZES MEB OF THE EPITAXY LAYER: A) SEEN OF PROFILE OF SIP(100) AND B) SIP (111), 20\% OF POROSITY

Figure $3 \mathrm{a}$ and $\mathrm{b}$ represent micrographics of two samples after epitaxy in liquid phase. The difference in morphology between these two layers undoubtedly comes from the presence from native oxide on the surface from the porous one. The porous layer resulting from a substrate of orientation (111) adapts better to such a growth by LPE owing to the fact that the speed of side growth is more important [7].

\section{A. Characterizations of the layers epitaxy on silicon by SIMS}

At present we are to detail the characteristics of the layers of silicon obtained by epitaxy on porous silicon: crystallinity, purity and morphological [11].

\section{B. Doping of the layers on porous silicon}

To characterize the doping of the layer epitaxy on porous silicon, the analyses SIMS was carried out in the down samples on taken its having various levels of doping. Profile SIMS was carried out on an epitaxy layer then detached. The latter was then engraved by plasma opposite back to remove residual porous silicon and analysis SIMS was carried out on this back face. The results are deferred on figure 4.

The unhooking of the layer of epitaxy is carried out within the fragile layer of porous silicon of strong porosity. The layer of low porosity restructured is thus on the back face of the detached layer. We then had recourse to attack plasma to engrave this residual layer, but, as profile SIMS shows it, engraving plasma was not sufficient. We thus find a part of layer of low porosity restructured $\left(N=1.10^{18} \mathrm{~cm}^{-3} \mathrm{~A}\right)$, then the zone of transition between porous substrate and layer epitaxy which extends on a thickness from $0,6 \mu \mathrm{m}$ approximately, before the future layer activates doping $N=2.10^{16} \mathrm{~cm}^{-3 A}$.

The comparison with analysis SIMS, under the same conditions, of a standard not comprising fluorine, enables us to affirm that the fluorine concentrations raised are not significant: the stage of anodization thus does not induce incorporation of fluorine in the epitaxy layers.

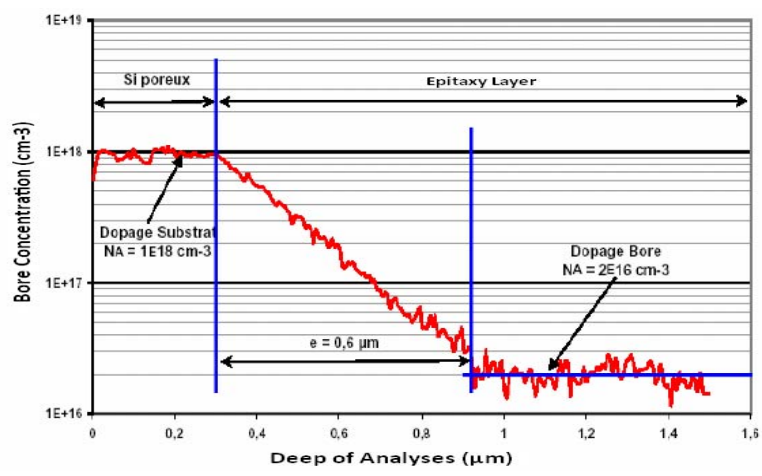

FIGURE IV. PROFILE SIMS OF BACK FACE OF EPITAXY ON POROUS SILICON $(\mathrm{NB}=2.1016 \mathrm{CM} 3)$.

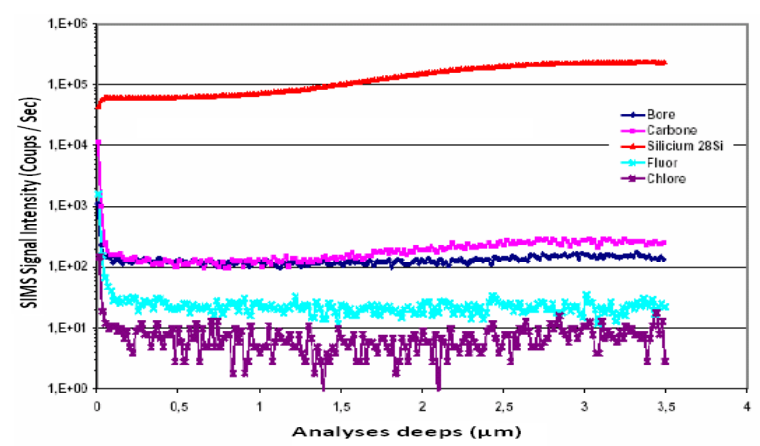

FIGURE V. CONCENTRATIONS IN IMPURITIES OF A LAYER EPITAXY ON POROUS SILICON

\section{CONCLUSION}

This study enabled us to characterize the quality of the layers epitaxy on porous substrate. An electrochemical attack is carried out on a silicon substrate, with the time and densities of current variable in such manner to obtain two layers of gradual porosities being formed from surface. The passage of porosity opens to a closed porosity, associated the creation of a singlecrystal layer on the surface, and authorizes the resumption in epitaxy. The study of the structural properties of the layers epitaxy on porous silicon shows that these last are singlecrystal and the not present of impurity. Finally we proved the feasibility of the unhooking of the layers epitaxy on porous silicon.

\section{ACKNOWLEDGMENT}

The authors thank the Chongqing Science and Technology Commission (contract grant number 2015cstc-jbky00103) (contract grant number cstc2013jesf50003) and ministry of Science and Technology of the People's Republic of China (contract grant number 2015DFA51330) and Central Universities (Fundamental Research Funds XJK2014C007) and Southwest University (Start Foundation for the Doctors, grant No SWU113114) for the financial support.

\section{REFERENCES}

[1] L.T. Canham, Appl. Phys. Lett, vol 57, (1990), 1046.

[2] Ph. Roussel, V. Lysenko, B. Remaki, G. Delhomme, A. Dittmard, D. Barbier, Sensors and Actuators, Vol. 74, (1999), 100-103. 
[3] Luca Boarino, C.Baratto, F. Geobaldo, G. Amato, E. Comini, A. M. Rossi, G.Faglia, G. Lérondel, G. Sberveglieri, Materials Science and Engineerieng B69-70, (2000), 210-214.

[4] K.Imai, Solid State Electron, Vol 24, (1981), 159.

[5] T. Yonehara, K. Sakaguehi end N. Sato, Appl. Phys. Lett, Vol. 64 (1994) 2018.

[6] R. Bilyalov, L. Stalamans, G. Beaucarne, R. Loo, M. Caymax, J. Poortmans, J. Nijs, Solar Energy Materials \& Solar Cells, Vol. 65 (2001), 477-485.7

[7] S.Berger, S Quoizola, A. fave, A. Ouldabbes, A. Kaminski, S. Perichon, D. Barbie and A. Laugier, 6th Polish Conference on Crystal GrowthSpecial Issue of CrystalResearch and Technology, 20-23 May (2001), Pozman-Pologne.

[8] H. Tayanaka, K Yamauchi,T.Matusushita, 2nd World Conference and Exhibition on Photovoltaic Solar Energy Conversion, Vienne-austria (1998), 1272-1277.

[9] W.Li. Liu, X. Z. Duo, L. W. Wang, M. Zhang, Q. W. Shen, C. L. Lin, K. C. Paul, Chin. Phys. Lett, Vol. 18, N5, (2001), 662-664.

[10] A.Bensaoula, K. Rerbal, S. Berger, S.Quoizola, S. Perichon, A. Kaminski, A. Fave, D. Barbier, A. Laugier. Congrés Euro Méditerranéen de la Matière Condensée 04-06 Juin (2001), TlemcenAlgérie.

[11] John P. Alper all. Journal of Nano Lett., (2014),14,(4),pp1843-1847.

[12] S. Quoizola, PhD theses (2003), Laboratoire de Physique de la Matière de L'INSA de Lyon -France.

[13] A. Bensaoula, PhD theses (2003), University of Tlemcen- Algeria 